\title{
HISTÓRIA E MEMÓRIA: ARQUIVOS E INSTITUIÇÕES ESCOLARES NA REGIÃO OESTE DO PARANÁ
}

\author{
João Carlos da Silva ${ }^{1}$ \\ Maria Valdeny Ferreira Gomes ${ }^{2}$ \\ Valdecir Antonio Nath ${ }^{3}$ \\ Lidiane Maciel Mufatto ${ }^{4}$
}

\section{RESUMO}

Resultado das atividades de pesquisa vinculadas ao grupo HISTEDBR/GT-Cascavel, PR, este artigo, calcado em estudo bibliográfico e levantamento em arquivos escolares, pontua alguns elementos históricos acerca da constituição da escolarização em Cascavel. O trabalho do pesquisador via de regra consiste na busca de papeis desorganizados cabendo a ele descobrirem onde localizá-los. Nesta empreitada muitas vezes é preciso superar obstáculos de ordem burocrática, da capacitação atendente na localização dos arquivos. $\mathrm{O}$ conhecimento da documentação visa levar alunos e professores a compreender a importância na reconstrução da memória institucional. A qualidade do conhecimento histórico depende da relação dos historiadores com as fontes. Desta forma, o desafio consiste em criar as condições objetivas para a preservação das fontes das Instituições Escolares selecionada, que possibilitem ao historiador buscar a explicitação da singularidade e da identidade histórica das Instituições Escolares.

Palavras-chave: História, Memória, Arquivos, Instituições escolares

\section{HISTORY AND MEMORY: FILES AND EDUCATIONAL INSTITUTIONS IN WEST REGION PARANÁ}

\begin{abstract}
Results of research activities related to the group HISTEDBR / GT-Cascavel, PR, this paper, based on literature research and survey on school records, scores on historical elements of the constitution of schooling in Cascavel. The researcher's work usually consists of seeking roles disorganized fitting it out where to find them. In this endeavor it is often necessary to overcome bureaucratic obstacles, the attendant at the training location of the files. Knowledge of documentation designed to lead students and teachers understand the importance of institutional memory in the reconstruction. The quality of historical knowledge depends on the relationship of historians to the sources. Thus the challenge is to create the objective conditions for the preservation of the sources of the institutions selected School, which allow the historian to seek clarification of the uniqueness and historical identity of the institutions School.
\end{abstract}

Keywords: History, Memory, Archives, Educational institutions

\section{Introdução}

A preocupação em relação á importância dos arquivos na pesquisa educacional ainda é recente e pouco disseminada. Essa perspectiva impõe aos pesquisadores da área, o desafio da preservação das fontes históricas em arquivos públicos e a constituição dos arquivos escolares. Pesquisar em arquivos é uma atividade dura e desafiadora, ao exigir muita paciência do pesquisador. O trabalho do pesquisador via de regra consiste na busca de papeis desorganizados cabendo a ele descobrir onde localizá-los. Nesta empreitada 
muitas vezes é preciso superar obstáculos de ordem burocrática, da capacitação atendente na localização dos arquivos. Nesta direção, a internet tem sido reconhecida como o novo recurso tecnológico para assegurar o acesso à documentação e a informação.

No Brasil, as políticas de arquivos, são regulamentadas mediante um arcabouço legal estando presente na Constituição Federal, decretos, portarias, resoluções, legislações estadual e municipal e instruções normativas. A Lei $\mathrm{n}^{\circ}$. 8.159, de 08 de janeiro de 1991 dispõe sobre a Política Nacional de Arquivos Públicos e Privados considerando-os em seu Art. $2^{\circ}$ : "Os conjuntos de documentos produzidos e recebidos por órgãos públicos, instituições de caráter público e entidades privadas, em decorrência do exercício de atividades específicas, bem como por pessoa física, qualquer seja o suporte da informação ou a natureza dos documentos".

Na década de 90, por conta da ideologia neoliberal disseminou-se a ideia entre os gestores a transposição de teoria da administração empresarial nos serviços públicos, com repercussão nas escolas. A partir deste pressuposto foi comum a pratica de gestão fundamentada na teoria da Qualidade Total e dos 5 "s" em que foram feitas a "limpeza" documental sob a justificativa que deveria ser removida a sujeira, jogar fora aquilo que seriam considerados papéis velhos. $\mathrm{O}$ que não foi descartado, acabou sendo empilhado em locais inadequados, jogados as traças e cupins.

A situação precária dos acervos das escolas tem sido um dos problemas mais observados, consistindo na eliminação indiscriminada dos documentos. O conhecimento da documentação visa levar alunos e professores a compreender a importância na reconstrução da memória institucional. Pretendemos com este artigo calcado, em estudo bibliográfico e levantamento em arquivos escolares, pontuar alguns elementos históricos acerca da constituição da escolarização em Cascavel.

\section{Fontes e instituições escolares}

Segundo Saviani (2007), o conceito do termo instituição origina-se do latim institutio, onis, e apresenta uma variação de significados, podendo caracterizar-se como sendo: plano, disposição, ordenação, instrução, criação, método e /ou sistema. Entende-se que o termo "instituição", em sentido geral, compreende algo que não está concebido naturalmente, ou seja, pronto, mas que é produzido e constituído pela ação do homem. A instituição, representada por uma estrutura material é organizada para atender determinadas necessidades humanas.

Neste sentido, as instituições escolares surgem para atender determinadas necessidades humanas, contudo não é toda e qualquer necessidade que requer a existência de uma instituição, pois o homem na procura de suas necessidades realiza-as num primeiro momento, como atividade espontânea e informal. É somente no processo que determina que uma atividade se institucionalize, e que desta forma se constitua, para satisfazer muito mais do que uma necessidade emergencial.

Segundo Maria Elisabeth Blanck Miguel (2007), na educação escolar, quer pelo seu aspecto político ou de sua cultura escolar, seus questionamentos podem levar o pesquisador até a escola. Pelo jeito de considerar a escola como um local de espaço concreto para a realização de todo o sistema de transmissão e construção do saber. Assim percebemos que os registros são de fato importantes e essenciais para uma pesquisa histórica. Logo, também podemos fazer a análise de que os registros das escolas, podem relatar acontecimentos e características escolares e não escolares, pois, a escola proporciona um grande processo de transição, pelo que envolve-se setores sociais, políticos e culturais; levando em conta características locais de acordo com a região onde a mesma pode estar instalada. 
Encontramos estas percepções quando Miguel diz:

Foi ainda possível compreender o modo como tais escolas, embora sob normas e leis estatuais e federais, interpretaram as recomendações e sugestões de modo bastante peculiar, dando-lhes um caráter especial e, quando da vivencia delas, faziam-no de maneira específica e original.(...)As fotografias que registraram os eventos testemunhavam a originalidade e as diferentes percepções que cada escola tinha sobre o mesmo tema (MIGUEL, 2007, p. 33).

Trata-se então que os levantamentos e análises de documentos podem ser elementos fundamentais para compreender o desenvolvimento histórico escolar com os seus aspectos políticos e sociais; como meio de nos apresentar, contar ou comunicar a maneira ou método de como foi este processo do desenvolvimento histórico.

Desta forma, fica evidente que para uma boa pesquisa, devemos levar em conta não só os registros com os levantamentos e análises por si só, mas sim considerar todos os fatores que contribuíram para que as tais atividades ou acontecimentos ocorressem. Portanto, temos que desenvolver condições necessárias para movimentar e elaborar a pesquisa das instituições escolares através das fontes e arquivos como um todo e não como um caso isolado. Então fica claro a importância e a influencia que as fontes e arquivos têm para contribuírem nos estudos de conhecimentos da história das instituições escolares e não escolares, pois afinal elas se situam em uma totalidade.

As instituições também precisam se auto-reproduzir, visando manter as suas próprias condições de produção, de acordo com as condições sociais que as estabeleceram e que explicam o seu funcionamento. Dessa forma, às instituições educativas, neste caso, a escola, aplica-se a mesma prática de produção e reprodução das relações sociais.

Nesta perspectiva, ao se pensar a história das instituições escolares no Brasil, Saviani (2007, p. 24), ainda discute que a mesma precisa ser retratada como a "reconstrução" histórica, porque o objeto do historiador, neste caso, a instituição escolar, não é construído pelo pesquisador. O que ele constrói é o conhecimento do objeto e isto significa reconstruí-lo no plano do pensamento.

A intencionalidade de pesquisa acerca da instituição escolar deve ser entendida mediante princípios delineados para além do interior de uma instituição escolar, ou seja, a partir das condições materiais que o fizeram ser produzido.

Sobre isso, recorremos a Marx:

O concreto é concreto porque é a síntese de muitas determinações, isto é, unidade do diverso. Por isso, o concreto aparece no pensamento como o processo da síntese, como o resultado, não como ponto de partida, ainda que seja o ponto de partida efetivo e, portanto, o ponto de partida também da intuição e da representação (MARX, 1977, p.28).

Com relação à instituição escolar, Sanfelice (2007), afirma que:

As instituições não são recortes autônomos de uma realidade social, política, cultural, econômica e educacional. Por mais que se estude o interior de uma instituição, a explicação daquilo que se constata não está dada de forma imediata em si mesma. Mesmo admitindo que as instituições adquirem uma identidade, esta é fruto dos laços de determinações externas a elas e, como já dito, "acomodadas" dialeticamente no seu interior. (SANFELICE, 2007, p. 78-79) 
Assim, não há instituição sem história, sem significado, de acordo com o contexto em que se insere. Com isso ao debruçarmos diante do desafio de compreender uma instituição em suas múltiplas dimensões, é possível creditar-lhe um novo sentido, com outros elementos, que até então não haviam sido apresentados à instituição, resignificando, portanto a sua identidade histórica.

\section{Instituições escolares na Região Oeste do Paraná}

O Oeste paranaense, ocupado efetivamente entre os anos de 1940 e 1970, foi marcado direta e imediatamente pelo impacto provocado pelas transformações sociais, científicas e tecnológicas que estavam ocorrendo no país naquele momento. Entretanto, antes de ocorrer a colonização propriamente dita, a região era ocupada por índios, principalmente da tribo dos guaranis que, perseguidos pelos bandeirantes, tiveram que fugir para a Região dos Sete Povos das Missões no Rio Grande do Sul, para o Uruguai e Paraguai. Assim como nas demais regiões do Brasil, a primeira preocupação dos colonizadores era com a posse da terra. Tentativas de colonização provocaram a perseguição, escravização e morte de muitos povos nativos, bem como a destruição predatória do meio ambiente. Inicialmente a economia era baseada no extrativismo vegetal, principalmente da erva mate.

A ocupação efetiva, da mesma forma que a época e as condições de desenvolvimento, assumiram características específicas. A ocupação efetiva do Oeste do Paraná foi realizada por colonos vindos do Sudoeste do Paraná e, mais tarde, por colonos italianos e alemães procedentes do Norte do Rio Grande do Sul e Oeste de Santa Catarina.

$\mathrm{O}$ processo de urbanização do município de Cascavel ocorreu simultaneamente às mudanças que se desencadearam no panorama histórico nacional, mais precisamente a partir da década de 50 até os anos 70, instante em que o país passou por um processo de mecanização agrícola e implantação de indústrias, substituindo gradativamente a agricultura manual. Este período caracterizou-se pelo modelo nacional-desenvolvimentista, baseado na industrialização.

Cascavel inicialmente pertencia ao Distrito de Foz do Iguaçu, emancipou-se somente em 14 de dezembro de 1952. Devido à sua localização geográfica, sempre foi muito bem vista pelos colonos pioneiros que visitavam frequentemente a região, pois queriam torná-la um pólo-regional, visando à exploração de suas terras, no espaço urbano disputado constantemente para a instalação de indústrias.

No auge do desenvolvimento industrial, é que o município de Cascavel crescia economicamente, com a produção de suínos, soja, café e madeira, principalmente, e tal processo tendia a vigorar nas próximas décadas. Aos poucos a ocupação urbana se configurou, instalando-se os latifundiários, que modernizaram o cultivo da terra, utilizando ferramentas sofisticadas, para atender às exigências do mercado, prejudicando os colonos que trabalhavam com a terra, para obter o sustento, aumentando o contingente de imigrantes, e expandindo a população de maneira acelerada.

No cenário do regime militar, muitas tensões ocasionadas em âmbito nacional atingiram cascavelenses que tiveram relação com o populismo de Vargas, e sofreram perseguições pelo golpe de 64. Neste contexto, Cascavel ainda enfrentou um processo eleitoral, com vitória de Odilon Damaso Correa Reinhardth. Um ano depois, o município considerado pólo, apresentava infraestrutura limitada, com poucos hospitais e saneamento básico e asfaltamento, em condições ainda precárias. 
Diante de manifestações de professores e movimentos estudantis, pela reivindicação de uma instituição de ensino superior, em 69 foi aprovada a criação da primeira faculdade, que seria de: Filosofia, Ciências e Letras. Também neste mesmo ano, criou-se a AMOP (Associação dos Municípios do Oeste do Paraná), uma instituição que visava agrupar os municípios dos arredores e potencializar a economia da região.

Foi no ano de 1969 que a mecanização desenfreou-se no território cascavelense, devido às influências de um modelo econômico internacional europeu transplantado para o país. Esse fator foi utilizado como instrumento para reacender a vida política e financeira do Brasil, que enfrentava problemas de ordem econômica e social, e os agricultores foram incentivados a preparar a terra com o emprego de técnicas modernizadoras, para satisfazer o mercado mundial.

Na década de 70 , o ciclo madeireiro já se esgotava pela extração de inúmeras árvores nativas. As indústrias eram mais de mil, a produção de suínos expandia e a população atingia a estatística de quase 90.000 residentes. Nessa época, foi implantado o sistema cooperativista, em que agricultores das regiões oeste e sudoeste do Paraná, buscavam soluções para a grande produção de soja e a sua venda a preços baixos, ausência de infraestrutura, como local para armazenamento da produção e transporte da mesma. Em 1972 ocorreu a implantação da Faculdade de Filosofia, Ciências e Letras de Cascavel, pela persistência de estudantes e professores.

Em 73, a soja era o principal produto exportado. No ano seguinte, o município cascavelense possuía mais de 500 indústrias, de diferentes atividades profissionais e sua população era jovem, com a maior parte da faixa etária inferior a 30 anos. Em 76, estabeleceu-se o Núcleo Regional da Secretaria de Estado da Agricultura, como reconhecimento da localização prestigiada que o município ocupava e pelas terras férteis que tinha. Com a exaustão da madeira, outros perfis de trabalhadores começaram a habitar a cidade, como profissionais especializados na mecanização da agricultura e construção, por causa da edificação de uma usina que ocorreria e por que a arte de cultivar a terra se alargava.

Assim, percebe-se que o processo de urbanização cascavelense ocorreu paralelamente aos fatos históricos nacional e mundialmente, e que o município foi se incorporando como um espaço urbanizado pela vinda de imigrantes e migrantes à região, que exploraram suas terras e modernizaram a agricultura.

Na Região Oeste, favorecido por sua posição geográfica e econômica, Cascavel impõe-se politicamente sobre os demais municípios. Segundo o IBGE (2007), atualmente, sua população é estimada em 286.205 habitantes. À medida que foi aumentando a produção, cresceu a população e a economia se inseriu no contexto nacional e trouxe junto o êxodo rural. Assim, de uma região eminentemente rural no passado, a partir dos anos 80 com os processos de desenvolvimento e com a inserção da tecnologia no campo, hoje predomina a urbanização, trazendo junto novos desafios. Neste contexto, a escola constituiu-se uma das primeiras e principais preocupações e a educação tem se constituído num importante fator de lutas e mobilizações sociais.

Conforme Emer (1991), a escolarização na Região Oeste do Paraná, passou por quatro fases a saber: escolarização particular domiciliar, casa escolar particular, casa escolar pública e grupo escolar.

No início da década de 30, Cascavel tinha a escolarização no modo de Casa Escolar Particular, no qual era desenvolvido em uma capela construída e financiada pelos moradores. Ao fim desta mesma década, já dispunha do modo de instrução realizado pela Casa Escolar Pública, e em 1947 possuía a escolarização nos moldes de Grupo Escolar.

Sobre a expansão da escolarização: 
O Oeste do Paraná, na década de 1960, começou a tomar corpo e definirse uma estrutura educacional. No período, além dos 18 núcleos urbanos, sede dos municípios, neles existindo grupos escolares públicos, confessionais e particulares, grupos escolares municipais nas principais vilas do interior dos municípios, a população urbana passou a reivindicar outros níveis de escolarização a partir da ampliação e complexificação das relações sociais já estabelecidas na região. A década de 1960 foi marcada pela implantação de escolas de nível ginasial, públicas e privadas; de Escolas Normais Colegiais públicas e particulares; de Escolas de Contabilidade exclusivamente particulares, e de um único Curso Científico, em Cascavel [...] Para o trabalho urbano, no comércio, em bancos e nos serviços públicos essa escolarização era necessária e a condição de acesso para ocupar as oportunidades de trabalho mais remunerado e os espaços de expressão política e de conceituação social (EMER, 1991, p. 17).

Neste sentido, a criação das primeiras escolas em Cascavel representou a concretização no Oeste do Paraná do projeto de educação nacional, com suas características próprias de uma cidade e região com predominância de imigrantes de diferentes nacionalidades.

A partir dos anos 70, a região de Cascavel, acompanhando o processo crescente de modernização e urbanização das cidades, ocorreu o processo de implantação das indústrias. Com isso, o ensino elementar passou a ganhar importância neste contexto de progresso e desenvolvimento econômico, visto que a oferta de trabalho e escolarização atraiu a vinda de pessoas de diferentes regiões para o município.

A proposta de resgate da reconstrução histórica das Instituições Escolares defrontase com dois problemas presentes nas investigações da História das Instituições Escolares, que são: o trabalho de levantamento e catalogação de fontes diante das precárias condições de armazenamento e manutenção pelas escolas públicas e o trabalho de articulação dos diversos tipos de fontes, de modo a não deixar escapar as características e o significado do fenômeno investigado (SAVIANI, 2007).

O processo de resgate das fontes das Instituições Escolares e de escrever a história destas Instituições amplia as possibilidades de compreensão da própria História da Educação, na medida em que elas se relacionam com o todo, e não é uma mera subdivisão da educação. A reconstrução histórica depende essencialmente das fontes, que são o ponto de origem, a base e o ponto de apoio para a produção historiográfica.

O resgate das fontes das Instituições Escolares ganha significado na medida em que traz a expressão de sujeitos ou grupos sociais específicos, que representam um contexto histórico determinado, sendo relevantes para compreensão da História da Educação de uma sociedade. No entanto, temos verificado em pesquisas anteriores, que a situação de manutenção das fontes pelas escolas públicas não é muito diferente da maioria dos acervos de Instituições Escolares do restante do país, com documentação dispersa, sem qualquer acondicionamento, deteriorando-se e sendo perdida. As Instituições Escolares, salvo pouquíssimas exceções, não têm a cultura que leve a uma prática continua de preservação de fontes. Encontramos com freqüência a existência do arquivo morto como um amontoado de papéis, caixas velhas, instalados em cubículos, porões ou banheiros quebrados, onde a poeira, a umidade e as traças se encarregam de executar a deterioração do material. 
Diante desta realidade vimos a necessidade de concentrar esforços no sentido da pesquisa histórica regional e que se realize o resgate das fontes, bem como, se consiga o envolvimento das escolas na preservação da memória institucional da Escola Pública.

Desta forma, o nosso empenho é de criar as condições objetivas para a preservação das fontes das Instituições Escolares selecionada para esta pesquisa, que possibilitem ao historiador buscar a explicitação da singularidade e da identidade histórica das Instituições Escolares.

\section{Arquivos, fontes e documentos escolares}

Miguel (2007) considera que a documentação de instituições escolares, nem sempre está à disposição do pesquisador, em arquivos e de maneira organizada, o que faz com que esta busca, seleção e ordenação das fontes configurem-se como uma das primeiras etapas do trabalho a ser desenvolvido. No levantamento de dados sobre o objeto, podem ser constituídos novos caminhos à pesquisa, dependendo do material de acesso e das interpretações feitas dos arquivos encontrados, buscando assimilar e resignificar o porquê de eles estarem ali registrados.

A partir do momento em que ocorre o contato do historiador com os arquivos disponíveis sobre seu objeto de pesquisa, pode-se redimensionar e determinar um plano de ação, pautado nas fontes e documentos escolares dos quais se depara, e presume a possibilidade de investigação de acordo com o conteúdo que os materiais analisados contem.

Neste sentido, vejamos às palavras da autora, ao considerar que

[...] para compreender melhor o que as fontes comunicam, se faz necessário que elas mesmas sejam consideradas dentro de sua história e em um contexto mais amplo, pois a compreensão da história das instituições escolares guarda uma profunda inter-relação com a história do contexto no qual tais instituições se situam (MIGUEL, 2007, p.38).

Ao estar diante dos arquivos, fontes e documentos escolares, são fundamentais que os mesmos sejam pensados em um contexto amplo, na articulação da singularidade com a totalidade. As fontes e os documentos escolares são produzidos historicamente pela humanidade, e consequentemente implementados em um período histórico, cujas necessidades produzidas justificam a necessidade de sua existência. É preciso considerar o fato de que ao se investigar uma instituição, nem sempre seus arquivos, fontes e documentos para fins à análise histórica estão necessariamente guardados ou presente no interior da instituição, podendo ser encontrados em outras dependências, visto que muitas vezes, as instituições escolares, não preservam de maneira adequada sua memória por meio de seus documentos temporais, que não são de uso imediatista.

Assim, é necessário considerar a relação de interdependência que há entre os arquivos, as fontes e os documentos escolares. Os primeiros só se constituem por ora como fontes, na medida em que são interpretados numa dimensão de totalidade do que manifestam, enquanto registro ou testemunho. Os documentos escolares, por sua vez, são eleitos como tal, quando expressam a materialidade da instituição escolar investigada, ou seja, a sua razão de existência histórica e social.

Nesta perspectiva, Le Goff (1994) em História e Memória, nos alerta que documento não é qualquer coisa que fica por conta do passado, mas é resultado produzidos pelas relações de forças que detinham o poder na sociedade. Os elementos que propiciam a produção a respeito da história das instituições escolares podem contribuir 
significativamente com uma pesquisa, quando os mesmos são utilizados como meio de explicação de um fenômeno para além de sua aparência, sendo interrogados e argumentados no presente, articulados ao momento em que foram produzidos.

Segundo Vidal (2007), a relevância do espaço destinado ao arquivo na instituição e a ampliação do conhecimento sobre documento escolar relacionam- se à cultura e às práticas escolares desenvolvidas no interior de uma instituição, como: "relação entre arquivos corrente e permanente; natureza do documento em educação; problemática do descarte e finalidade de preservar a documentação escolar" (Idem, p. 64). Estes documentos são valorados diferentemente, de acordo com os sujeitos que fazem uso e podendo ser eles de ordem burocrática, para o cumprimento de objetivos imediatos aos gestores da educação e os documentos antigos, considerado no âmbito escolar como arquivo morto, mas que para os historiadores da educação, constituem a preservação da memória histórica.

Nesta perspectiva, Vidal ainda sugere a existência de um trabalho integrado entre as secretarias de escolas, os arquivistas e os historiadores da educação, em que elaborem planos de destinação a estes documentos, o que remete também a reflexão do que define um documento escolar e o que se deve preservar ou descartar nos arquivos. Aborda que a natureza do documento em educação é escrituraria, pois é no espaço escolar, que se encontram os resultados das relações pedagógicas e burocráticas, por meio de diários de classes, históricos escolares, exames, boletins, cadernos de alunos, ou seja, registros realizados por professores, alunos e pela gestão da escola, que caracterizam o funcionamento e as práticas da instituição escolar.

Assim, é possível perceber que o documento escolar, deve ser entendido em um contexto amplo, considerando como tal não apenas os arquivos com registros escritos, mas também os testemunhos orais, e ainda a própria organização material da instituição, que incluída à sua arquitetura, revela por meio da sua disposição, relações entre os sujeitos que a utilizam.

De acordo com Saviani (2004) o conceito de fonte precisa ser analisado em um determinado contexto, podendo assumir diversos significados no campo da historiografia. Uma fonte a princípio tem dois sentidos: por um lado pode ser o ponto de partida, de onde procede algo planejado e este se desenvolve, e também por outro indica a base, o ponto de apoio, o local em que se encontram os elementos inesgotáveis e que permitem a possibilidade de explicação de um fenômeno (Idem, p.4 e 5).

Saviani sugere que de acordo com a contextualização de fonte, a sua conjuntura de análise pode comunicar diversas percepções, porque ela se constitui como um respaldo às ideias defendidas. Assim, a abstração do pensamento é elaborada pela materialidade, e que necessita de cientificidade para sua afirmação, e também demonstra que promove diálogo com quem a questiona enquanto produção histórica.

No caso da história, as fontes não são naturais, mas históricas, pois correspondem à produção humana e, portanto representam o ponto de origem dos saberes que o historiador dispõe para produzir o conhecimento sobre a história. Explica também que é necessário diferenciar as fontes fundadas de modo espontâneo e as constituídas intencionalmente.

Elas encontram-se em diferentes acervos como documentos, vestígios acumulados e guardados para serem recorridos quando precisos. Ressalva por precisão que só podem ser nomeadas "fontes", as que o historiador produz como conhecimento histórico, entendendo que na sua essência, as fontes para a historiografia não são interpretadas como eventos prontos e espontâneos (idem, 5-7). 
Neste sentido, ressaltamos que as fontes são entendidas não apenas como registros que foram sendo acumulados ao longo da história, mas como documentos provenientes de forças econômicas e políticas e, ou seja, dos projetos de sociedade em disputa.

\section{Fontes e Instituições Escolares}

As fontes representam um vínculo simultâneo entre o passado, o presente e o futuro, na medida em que quando são produzidas em determinado período histórico, resultam no presente as marcas de seu registro e assim ao tempo em que são interrogadas pelos sujeitos na atualidade, propiciam diferentes inferências sobre o conhecimento que apresentam, e desse modo reconstroem-se a partir da análise realizada por quem se esforça em entendê-las nas suas múltiplas faces. Elas também contribuem com a posteridade, ou seja, com os fatos futuros, porque possibilitam o desenvolvimento de outros trabalhos, visto que, quanto mais fontes forem selecionadas, organizadas e arquivadas, mais oportunidades de compreensão das transformações históricas serão oferecidas aos pesquisadores que se propõem a reconstruir a história das instituições escolares.

De acordo com Saviani (2004), devem ser observados os critérios de escolha das fontes para a história das instituições escolares, pois os mesmos dependem do objeto e objetivos da pesquisa, bem como da delimitação, ou seja, do período histórico projetado à investigação. Desta forma, não é qualquer registro que apresenta pistas para a compreensão da história das instituições escolares.

Para Lombardi (2004), as fontes precisam da ação do homem para que sejam produzidas, registradas e analisadas, e é imprescindível que o historiador delimite o seu objeto de estudo e busque fontes que contribuam para reconstruí-lo no plano do pensamento. Se necessário, deve também recorrer a diferentes tipos de fontes, como: testemunhos orais, documentos escritos, produções iconográficas, audiovisuais e eletrônicas encontradas na internet. É preciso pensar numa dimensão de ampliação e utilização de documento, não descartando que a diversificação pode trazer elementos significativos à compreensão das relações do homem com outros homens e com o meio em que vive.

As fontes selecionadas para reconstituir a história das instituições escolares não podem ser somente aquelas que se encontram o interior da escola. Assim, devem-se estabelecer critérios na escolha das fontes, pois as mesmas não respondem às relações entre o objeto e o seu contexto, quando se restringem ao contexto escolar, e não ao contexto da sociedade.

Existem diferentes tipos de fontes que podem ser utilizadas pelo pesquisador. Além da arquitetura da instituição, dos documentos oficiais, como: leis, decretos, pareceres, testemunhos escritos, Ata de fundação, relatórios, fotos, jornais impressos e materiais da internet. Conforme já afirmamos, os relatos orais podem também ser considerados fontes de tal valor, quando direcionados pelo pesquisador.

Segundo Werle (2004), a história das instituições escolares possibilita falar sobre monumentos, monumentos/documentos, relatos orais e memórias, relacionando-se os termos uns com os outros. Explica que os monumentos são prédios estruturados vinculados à base material das instituições e que estes também são documentos. A escola é tomada como monumento, a partir das relações de poder que marcaram esta instituição e que por meio da memória são possíveis de reconstrução, estando ainda em funcionamento ou não existindo mais.

Assim, a base material da escola pode ser pensada tanto como o espaço físico (estrutura arquitetônica), como a organização de uma determinada proposta pedagógica, 
que direciona a instituição escolar. Desse modo, mudanças na base material, podem causar transformações nos modos de interação entre os agentes da instituição escolar (alunos, professores, pais). Uma nova forma de disposição do espaço pode ser ponderada como desrespeito pelos sujeitos que já viveram na instituição, em que as lembranças e memórias da sua história, foram suprimidas pelo espaço modificado no presente, causando-lhes sensação de destruição da instituição, pelas mudanças ocasionadas.

Desta maneira, a ausência de preservação da memória institucional, é percebida individualmente como manifestações imprudentes, entretanto para outros é contemplada como inovação, pois vêem a renovação como uma expressão do aperfeiçoamento e crescimento da instituição, já que as reformas na modernidade são incentivadas entre as escolas, como significado de progresso. Ademais, é ainda preciso dizer que a memória da instituição escolar por meio de sua estrutura material se preservada adequadamente pode constituir- se como um documento e fonte para a história das instituições escolares.

Cabe ao pesquisador que trabalha com história das instituições educativas: reunir, confrontar, selecionar e analisar os documentos/monumentos presentes e pertencentes às escolas, fazendo com que sejam revelados os anseios das pessoas que servem à instituição escolar. Os documentos/monumentos não são vazios, mas são resultados de uma organização, consciente ou inconsciente, da história que o produziram, e que precisam ser desvelados em sua totalidade (Idem, p. 24).

Como explica Werle (2004) no processo de investigação em história das instituições escolares, é preciso ter alguns cuidados, pois ao escrever a narrativa, querer relatar o "documento na íntegra" pode constituir-se no registro aparente, sem crítica e problema da instituição, por redigir o documento como se tivesse uma história que falasse por si e que não precisasse da subjetividade do pesquisador ao fazê-la.

Também é necessário alertar para o fato de "adotar o discurso da história institucional oficial", pois principalmente quando a instituição ainda está em funcionamento, ela pode querer controlar a produção do pesquisador sobre a escola ou ainda pressioná-lo para que evidencie em seu trabalho um projeto da instituição, já que a escola proporcionou a ele o contato com os arquivos.

Outro risco é o de "buscar a descrição da totalidade da história institucional", porque ao tentar realizá-la na essência da totalidade, pode se desviar da análise prevista, dos seus interesses e escolhas para a pesquisa, entendendo também que se o sentido da história das instituições escolares é plural, o trabalho do pesquisador corresponde a um modo de se fazer a história da instituição, e não toda a história, pois existem diferentes histórias sobre uma mesma instituição escolar (WERLE, 2004, p. 29-30).

Percebe-se que os arquivos, as fontes e os documentos escolares assumem papel relevante, visto que constituem um dos alicerces ao desenvolvimento de pesquisas historiográficas sobre a história das instituições escolares. Eles precisam ser pensados em um contexto amplo, relacionados ao que representam à memória histórica, tendo que ser preservados e conservados, para testemunhar sobre o passado as relações de poder travadas entre diferentes grupos sociais, bem como as disputas por um determinado projeto de sociedade.

Neste sentido, o trabalho do pesquisador é promissor às oportunidades que ele tem, quando no contato direto com as fontes tem o poder de conferir-lhes significado, a partir do conhecimento histórico que elas constituem em si e que precisa ser interrogado em seu contexto de produção.

\section{Considerações finais}


Diante das reflexões apontadas, percebemos o quanto é importante e necessário à pesquisa referente à história das instituições escolares, pois a partir do resgate histórico sobre elas podemos compreender melhor por que a escola se materializa de tal forma no presente, quais os determinantes que a fizeram constituir-se enquanto um projeto de sociedade, analisando o movimento histórico nesta relação interdependente entre o passado e o momento atual, entendendo que o primeiro possibilita por meio das fontes a investigação e análise histórica sobre os fatos que estabeleceram a existência de instituições escolares.

Por esta razão, reafirmamos a necessidade de continuar pesquisando os arquivos que possam contribuir para a produção historiográfica sobre a História da Educação Brasileira, neste caso, de uma instituição local, no município de Cascavel, mas que estabeleceu relações em nível regional e nacional, fazendo assim uma intersecção simultânea entre o singular e o universal, na tentativa de compreender o objeto em uma dimensão de totalidade dos fatos históricos.

A qualidade do conhecimento histórico depende da relação dos historiadores com as fontes. E uma relação mais sólida com as fontes, só vai ser possível, quando ele não precisar gastar boa parte do tempo de pesquisa para localizá-las nos arquivos. Desta forma, o desafio consiste em criar as condições objetivas para a preservação das fontes das Instituições Escolares selecionada, que possibilitem ao historiador buscar a explicitação da singularidade e da identidade histórica das Instituições Escolares.

\section{Referências}

EMER, Ivo Oss. Desenvolvimento do Oeste do Paraná e a construção da escola. RJ. Fundação Getúlio Vargas, 1991 (Dissertação de Mestrado).

LOMBARDI, José Claudinei; NASCIMENTO, Maria Isabel Moura de (orgs.). Fontes, história e historiografia da educação. Campinas, SP: Autores Associados: HISTEDBR; Curitiba, PR: Pontifícia Universidade Católica do Paraná (PUCPR); Palmas, PR: Centro Universitário Diocesano do Sudoeste do Paraná (UNICS); Ponta Grossa, PR; Universidade Estadual de Ponta Grossa (UEPG), 2004.

MARX, KARL. Contribuição a crítica da economia política. S.P. Livraria Martins Fontes, 1977.

MIGUEL, Maria E. B. Do levantamento de fontes à construção da historiografia: uma tentativa de sistematização. In. NASCIMENTO, Maria Isabel Moura; SANDANO, Wilson; LOMBARDI, José Claudinei; SAVIANI, Dermeval (orgs.) Instituições Escolares no Brasil: conceito e reconstrução histórica. Campinas, SP: Autores Associados: HISTEDBR; Sorocaba, SP: UNISO; Ponta Grossa, PR: UEPG, 2007.

MORAES, Carmen Sylvia Vidigal; ZAIA, Iomar Barbosa; VENDRAMETO, Maria Cristina. Arquivos escolares e pesquisa histórica: fontes para o estudo da educação brasileira. Pró-Posições V. 16. N. 1(46) Jan/Abr. 2005.

NASCIMENTO, Maria Isabel Moura; SANDANO, Wilson; LOMBARDI, José Claudinei; SAVIANI, Dermeval (orgs.) Instituições Escolares no Brasil: conceito e reconstrução histórica. Campinas, SP: Autores Associados: HISTEDBR; Sorocaba, SP: UNISO; Ponta Grossa, PR: UEPG, 2007.

SAVIANI, D. Breves considerações sobre fontes para a História da Educação. In. LOMBARDI, José Claudinei; NASCIMENTO, Maria Isabel Moura (orgs.). Fontes, história e historiografia da educação. Campinas, SP: Autores Associados, 2004. 
SANFELICE, J.L. História das instituições escolares. In. NASCIMENTO, Maria Isabel Moura;SANDANO, Wilson; LOMBARDI, José Claudinei; SAVIANI, Dermeval (orgs.) Instituições Escolares no Brasil: conceito e reconstrução histórica. Campinas, SP: Autores Associados: HISTEDBR; Sorocaba, SP: UNISO; Ponta Grossa, PR: UEPG, 2007.

SPERANÇA, Alceu A. Cascavel: a história. Curitiba: Lagarto, 1992.

VIDAL, Diana Gonçalves. Instituições escolares no Brasil: conceito e reconstrução histórica: Por uma ampliação da noção de documento escolar. In. NASCIMENTO, Maria Isabel Moura; SANDANO, Wilson; LOMBARDI, José Claudinei; SAVIANI, Dermeval (orgs.) Instituições Escolares no Brasil: conceito e reconstrução histórica. Campinas, SP: Autores Associados: HISTEDBR; Sorocaba, SP: UNISO; Ponta Grossa, PR: UEPG, 2007.

WERLE, Flavia O. C. História das instituições escolares: de que se fala?In. LOMBARDI, José Claudinei; NASCIMENTO, Maria Isabel Moura (orgs.). Fontes, história e historiografia da educação. Campinas, SP: Autores Associados, 2004.

Notas

${ }^{1}$ Doutor em Filosofia, História e Educação/FE-UNICAMP. Professor do Curso de Pedagogia e do Programa de Pós-graduação/Mestrado em Educação da UNIOESTE, Campus de Cascavel. Membro do grupo de pesquisa HISTEDOPR - História, sociedade educação - Oeste do Paraná

${ }^{2}$ Mestrado em Educação pelo Programa de Pós-graduação/UNIOESTE, campus de Cascavel/PR. Professora da Rede Estadual de ensino em Cascavel. Coordenadora do Profuncionário.

${ }^{3}$ Mestrando em Educação pelo Programa de Pós-graduação/UNIOESTE, campus de Cascavel/PR Atual Secretário Municipal de Educação de Cascavel.

${ }^{4}$ Graduanda em pedagogia. Bolsista PIBIC/CNPQ/UNIOESTE, Campus de Cascavel.

Recebido em: $\quad 07.05 .12$

Aprovado em: $\quad 30.05 .12$ 